\title{
New Phosphonic Acid Functionalized, Regioregular Polythiophenes
}

\author{
Kristoffer K. Stokes, Karine Heuzé, and Richard D. McCullough* \\ Department of Chemistry, Carnegie Mellon University, Pittsburgh, Pennsylvania 15213 \\ Received May 15, 2003; Revised Manuscript Received J uly 30, 2003
}

\begin{abstract}
Here we present the synthesis of both regi oregular amphiphilic polythiophenes carrying a phosphonic acid on al ternating side chains (8) and a regi or egular polythiophene polyelectrolyte carrying a phosphonic acid side chain (14). We present the cation self-assembly and colorimetric changes of these regioregular polythiophenes carrying phosphonic acids. We also have explored the ability of these polymers to attempt to form SAMs with zirconium.
\end{abstract}

\section{Introduction}

The fabrication of nanoscale electronic and photonic devices derived from polymers could be implemented using the self-assembly of conducting polymers. The development of nanoscale self-assembly of conducting polymers at a variety of surfaces including thin films of metals, semiconductors, and diel ectric materials could be important in the fabrication of new nanoscale devices. However, the conducting polymer structures must be optimized for high electrical conductivity and selfassembled in an ordered fashion. A number of ways have been developed that produce ordered molecular scaffolds at surfaces by self-assembly including using the complexation reaction of phosphonic acids and metal ions of various valencies, particularly tetraval ent zirconium as developed by Mallouk in order to produce monolayers and multilayer structures. ${ }^{1}$ In addition, Talham et al. have used this phosphonic acid deposition procedure in conjunction with Langmuir-Blodgett techniques to form bilayer structures connected by a phosphonic acid-zirconium complex. ${ }^{2}$

The use of electronic molecular components such as oligo- and polythiophenes as designed components that can self-assemble into devices has been explored in the pioneering work by Garnier. ${ }^{3}$ In this work, quaterthiophenediphosphonic acid was used to create multilayer structures using the Mallouk deposition procedure with good results. Katz ${ }^{3}$ found that the conjugated backbone is perpendicular to the substrate, yet aligns to form oligothiophene assemblies. Other related work has focused on the use of assemblies where thiol adsorption to gold surfaces or el ectrostatic interactions to create layered structures. ${ }^{4}$ We were interested in exploring the use of regioregular polythiophenes bearing phosphonic acid side chains to form mixed metalconductive polymer layered structures. Here we present the synthesis of both regioregular amphiphilic polythiophenes carrying a phosphonic acid on alternating side chains (8) and a regioregular polythiophene polyel ectrolyte carrying a phosphonic acid side chain (14). We also have explored the ability of these polymers to form SAMs with zirconium and the ability of these polymers to undergo cation self-assembly.

\section{Results and Discussion}

Polythiophenes, by nature, are quite sensitive to their regiochemistry. ${ }^{5}$ Even if the molecules are ordered

\footnotetext{
* Corresponding author.
}

intermolecularly, the properties of the polymer are still inextricably tied to the intramolecular order. Thus, a regioirregular polymer that was designed to undergo self-assembly or intermol ecular ordering by a molecular recognition mechanism may lead to an organized three dimensional structure, yet the polymer properties would be diminished due to the lack of conjugation in the overall structure. On the other hand, the development of a regioregular polythiophene with an assembly mechanism not only may enhance the properties by incorporating order in three dimensions but also could lead to highly conductive nanoassemblies.

The synthesis of an amphiphilic copolymer of a regioregular polythiophene with a pendant alkyl phosphonic acid group could be used for the devel opment of a conducting polymer self-assembled monolayers or multilayers through a simple dipping deposition method as described above. ${ }^{6,7}$ In fact, very recent work has shown that under certain conditions irregular polythiophene phosphonic acids have been reported to form multilayers with zirconium. ${ }^{7}$ In addition, polythiophene polyelectrolytes could be assembled using a cationassembly mechanism as we have previously shown. ${ }^{8}$

The synthesis of polymer $\mathbf{8}$ is shown in Scheme 1 and requires the synthesis of the functional amphiphilic dimers of thiophene such as $\mathbf{4 , 5}$, and $\mathbf{6}$. A Stille coupling reaction between $\mathbf{2}$ and $\mathbf{3}$ in DMF led to amphiphilic dimer 4 in $50-60 \%$ yield. Sel ective bromination of 4 by NBS at $0{ }^{\circ} \mathrm{C}$ yielded dimer 5 in a $67 \%$ yield. Dimer $\mathbf{4}$ is reacted in a Michaelis-Arbuzov rearrangement in triethyl phosphite, which provided the phosphonate ester group on the hyrophilic side of dimer $\mathbf{5}$ in an $88 \%$ yield. Stannylation of dimer $\mathbf{5}$ followed by polymerization of 6 with Stille chemistry led to polymer 7. Deprotection of polymer $\mathbf{7}$ led to amphiphilic regioregular polythiophene 8.

It was found that the Stille polymerization method is superior to other methods that produce regioregular polythiophenes. ${ }^{9,10}$ The GRI M ${ }^{10}$ and Kumada ${ }^{9}$ methods are not compatible with the phosphonic ester moiety and yielded only short chain oligomers. The crude polymer was recovered from the Stille polymerization as a dark purple solid after precipitation in hexanes. Further fractionation/purification included a Soxhlet extraction with hexanes, followed by an extraction of the purified polymer 7 into chloroform. ${ }^{1} \mathrm{H}$ NMR characterization showed a highly regi oregular backbone as indicated by the single aromatic peak corresponding to head-to-tailhead-to-tail regiochemistry. GPC analysis of the chloroform fraction gave an $M_{n}$ of $21500 \mathrm{~g} / \mathrm{mol}$ with a PDI 
Scheme 1. Synthesis of Amphiphilic Polythiophene Phosphonic Acids
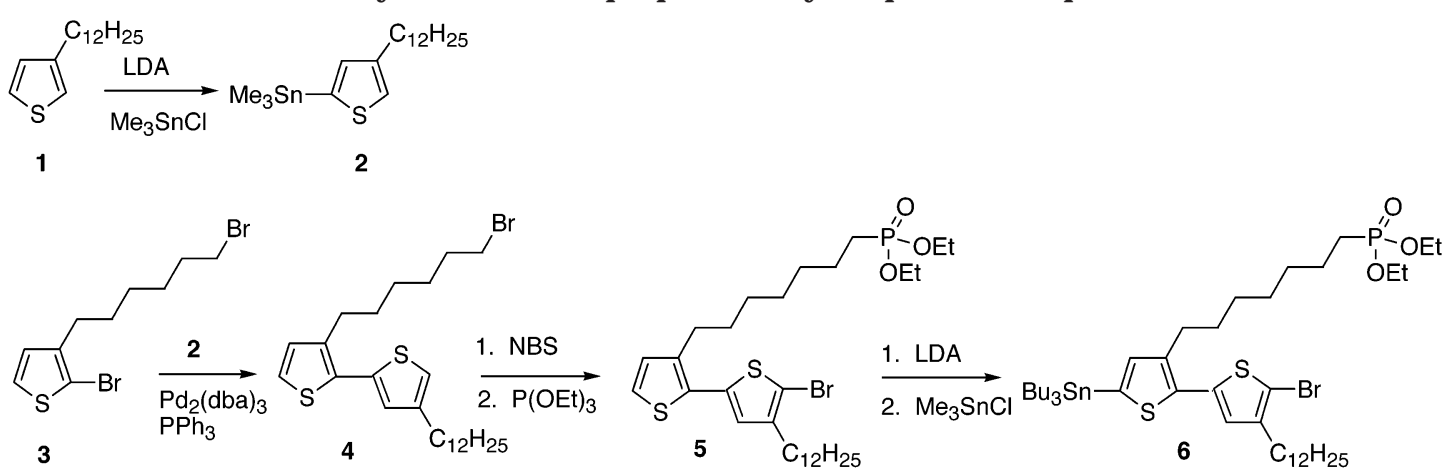

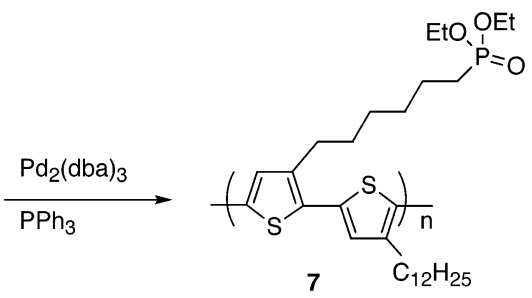

of 1.46. The UV-vis analysis exhibited a blue shift in the spectrum relative to polyalkylthiophenes as shown by a thin film that exhibited a $\lambda_{\max }$ of $542 \mathrm{~nm}$, while a $\mathrm{CH}_{3} \mathrm{Cl}$ solution had a $\lambda_{\max }$ of $443 \mathrm{~nm}$. Analysis by MALDI-MS showed peaks centered about 6K, separated by $552 \mathrm{~g} / \mathrm{mol}$, which is the molecular weight of the repeat unit. We believe that the MALDI experiment not showing all of the higher molecular weight polymers. We have experienced variability in mass characterization of regioregular polythiophenes that seemed to vary as the side chains vary. The phosphonate group on polymer $\mathbf{7}$ was then hydrolyzed with bromotrimethylsilane and methanol, leading to the phosphonic acid functionalized copolymer $\mathbf{8}$.

Polymer $\mathbf{8}$ was highly insoluble in both organic and inorganic solvents. However, the addition of tetraalkylammonium hydroxide salts led to the solubilization of 8. All tetraal kylammonium hydoxide solutions $\left(\mathrm{Bu}_{4} \mathrm{~N}^{+}\right.$, $\mathrm{Pr}_{4} \mathrm{~N}^{+}$, and $\mathrm{Et}_{4} \mathrm{~N}^{+}$) led to a soluble polymer with varying conjugation lengths. The $\lambda_{\max }$ of the UV - vis spectrum shifts according to the size of the counterion, a phenomenon that has previously been reported for carboxylic acid functional ized polythiophenes. ${ }^{8}$ While the $\lambda_{\max }$ was $443 \mathrm{~nm}$ in chloroform for the phophonic ester $7\left(\lambda_{\max }\right.$ of thin film was $542 \mathrm{~nm}$ ), the $\lambda_{\max }$ values obtained were $497 \mathrm{~nm}$ for the $\mathrm{Bu}_{4} \mathrm{~N}^{+}$salt, $534 \mathrm{~nm}$ for the $\mathrm{Pr}_{4} \mathrm{~N}^{+}$salt, and $532 \mathrm{~nm}$ for the $\mathrm{Et}_{4} \mathrm{~N}^{+}$salt. Solution self-assembly of the amphiphilic phosphonate polythiophene $\mathbf{8}$ was indicated by the large shift in the $\lambda_{\max }$ of solutions of the phosphonic ester $\mathbf{7}$ when $\mathbf{8}$ was dissolved in alkylammonium salts. Apparently, the cations help to organize solution self-assembly as has been shown ${ }^{8}$ in a regioregular polythiophene carboxylate dissolved in tetraal kylammonium hydroxide solutions. We hypothesize that the purple phase observed in aqueous propyland ethylammonium solutions of $\mathbf{8}$ occurs by a hydrophobic supramolecular assembly of the polythiophene backbone, with subsequent order being determined by salt-pairing of the side chains between the two rigid rods of polymer $\mathbf{8}$ (Figure 1). It is interesting to note that, in the absence of the cations, the polymer was fairly disordered. In addition, this method of solubilization by ammonium salts can be used to purify the polymer by

$$
\begin{array}{|l|l|l|l|l|}
\stackrel{+}{\mathrm{N}} \mathrm{R}_{4} & \stackrel{+}{\mathrm{N}} \mathrm{R}_{4} & \stackrel{+}{\mathrm{N}} \mathrm{R}_{4} & \stackrel{+}{\mathrm{N}} \mathrm{R}_{4} & \stackrel{+}{\mathrm{N}} \mathrm{R}_{4} \\
\stackrel{+}{\mathrm{N}} \mathrm{R}_{4} & \stackrel{+}{\mathrm{N}} \mathrm{R}_{4} & \stackrel{+}{\mathrm{N}} \mathrm{R}_{4} & \stackrel{+}{\mathrm{N}} \mathrm{R}_{4} & \stackrel{+}{\mathrm{N}} \mathrm{R}_{4} \\
\stackrel{+}{\mathrm{N}} \mathrm{R}_{4} & \stackrel{+}{\mathrm{N}} \mathrm{R}_{4} & \stackrel{+}{\mathrm{N}} \mathrm{R}_{4} & \stackrel{+}{\mathrm{N}} \mathrm{R}_{4} & \stackrel{+}{\mathrm{N}} \mathrm{R}_{4} \\
\stackrel{+}{\mathrm{N}} \mathrm{R}_{4} & \stackrel{+}{\mathrm{N}} \mathrm{R}_{4} & \stackrel{+}{\mathrm{N}} \mathrm{R}_{4} & \stackrel{+}{\mathrm{N}} \mathrm{R}_{4} & \stackrel{+}{\mathrm{N}} \mathrm{R}_{4}
\end{array}
$$

Figure 1. Proposed assembly of polythiophene phosphonic acids by cation assembly.

\section{Scheme 2. Polythiophene Phosphonic Acid Homopolymer}

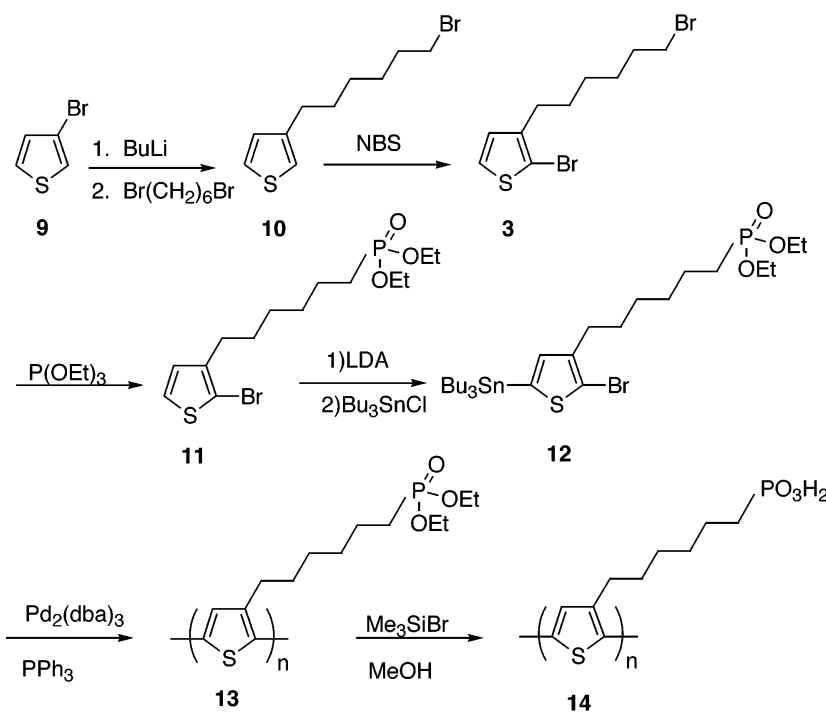

repeated precipitation in dilute aqueous $\mathrm{HCl}$ solution, followed by filtration.

The synthesis of regioregular polyelectrolyte polythiophene $\mathbf{1 4}$ is shown in Scheme 2. The synthesis required the attachment of a longer chain alkyl phosphonic ester, which was accomplished using a literature method. ${ }^{11}$ Compound $\mathbf{1 0}$ was synthesized by treating 3-bromothiophene with n-BuLi in hexanes and quench- 
ing the 3-lithiothiophene with 1,6-dibromohexane. Subsequent bromination of the 2-position with NBS led to 2-bromo-3-bromohexylthiophene (3) in an unoptimized $45-50 \%$ yield. Functionalization with triethyl phosphite, followed by metalation with LDA and quenching with tributylstannyl chloride, led to 12. Polymerization and deprotection of $\mathbf{1 2}$ and $\mathbf{1 3}$, respectively, were essentially the same as the method used for the synthesis of amphiphilic polymers $\mathbf{7}$ and $\mathbf{8}$. A Stille crosscoupling polymerization ${ }^{11}$ in DMF using triphenylphosphine and tri(dibenzylideneacetone)dipalladium led to regioregular phosphonic ester polythiophene 14. I solation of the purple powder by first washing with hexanes followed by dissolving remaining powder in THF led to polymer $\mathbf{1 4}$ in low yield. Analysis of the phosphonate ester by ${ }^{1} \mathrm{H}$ NMR again showed a high degree of regioregularity evidenced by the single peak in the aromatic region. The molecular weights were $\mathrm{M}_{\mathrm{n}}$ of $13 \mathrm{~K}$ by GPC (PDI = 1.9) and a molecular weight of 7K by MALDI. Again, selective fractionation by MALDI underrepresented the molecular weights. Hydrolysis of phosphonic ester polymer $\mathbf{1 3}$ with bromotrimethylsilane and water led to polythiophene 14. The neutral polymer 14 was insoluble in most solvents; however, the polymer was partially soluble in ethanol.

As with the amphiphilic phosphonic acid, the homopolymer was very soluble in basic aqueous ammonium hydroxide and tetraalkylammonium hydroxide solutions. The homopolymer exhibited a similar sensitivity to counterion size as reported above for the amphiphilic polymer 8. A typical $\lambda_{\max }=442 \mathrm{~nm}$ for the phophonic ester polythiophene $\mathbf{1 3}$ in chloroform (spincast film $\lambda_{\max }=524 \mathrm{~nm}$ ). Treatment with $\mathrm{n}-\mathrm{Bu}_{4} \mathrm{NOH}$, $n-\mathrm{Pr}_{4} \mathrm{NOH}$, and $\mathrm{n}-\mathrm{Et}_{4} \mathrm{NOH}$ led to little solution order as indicated by the UV-vis spectrum $\left(\lambda_{\max }\right.$ of $\left.465 \mathrm{~nm}\right)$ of the solutions, while aqueous $\mathrm{NH}_{4}$ solutions led to a $\lambda_{\max }$ of $510 \mathrm{~nm}$, indicating that some induced selfassembly of the phosphonate polythiophene polyelectrolyte did occur (Figure 1). In contrast, amphiphilic polythiophene $\mathbf{8}$ showed more propensity to hydrophobic/ polyelectrolyte self-assembly.

By utilizing coordination between tetravalent zirconium and the polythiophene phosphonic acids, we attempted to create self-assembled mono- and multilayers. However, the lack of sol ubility in the appropriate solvents leading to colloidal suspensions of $\mathbf{8}$ and $\mathbf{1 4}$ precluded any SAM formation. UV-vis experiments to monitor SAM multilayer deposition of for example 8 in water or ethanol mixtures with the base DBU on silylated glass, followed by treatment with $\mathrm{ZrOCl}_{2}$, drying, and repeat, led to a nonlinear increase in absorption. Despite repeated experiments, in our hands, we could not produce multilayers of $\mathbf{8}$ or $\mathbf{1 4}$. The electrical conductivity of thin films of $\mathbf{8}$ and $\mathbf{1 4}$ range from 0.01 to $1 \mathrm{~S} / \mathrm{cm}$.

\section{Conclusion}

Polythiophenes can now be synthesized with a pendant phosphonic acid functionality for use in selfassembled monolayer studies. Future work with these molecules will include Langmuir-Blodgett studies on the amphi philic polymer to determine monolayer stability as such a film as well as mono- and multilayer deposition studies to determine the capabilities of these molecules to form the desired supramolecular structures.

\section{Experimental Section}

All solvents used were distilled over an appropriate drying agent prior to use and reactions carried out under dry $\mathrm{N}_{2}$. Elemental analyses were performed by Midwest Microlabs, Indianapolis, IN.

Amphiphilic Copolymer Synthesis. 3-Bromohexylthiophene. 3-Bromothiophene $(30 \mathrm{~g}, 0.18 \mathrm{~mol})$ was dissolved in hexanes $(250 \mathrm{~mL})$, and the solution was cooled to $-40{ }^{\circ} \mathrm{C}$ to $-50{ }^{\circ} \mathrm{C}$. n-BuLi was then added dropwise, and the solution was stirred for $10 \mathrm{~min}$. Then, THF was added dropwise via a syringe (ca. 15-20 mL) until the white 3-lithiothiophene salt precipitated. The sol ution was then stirred for $1 \mathrm{~h}$, after which the solution was allowed to warm to $-10^{\circ} \mathrm{C}$. Dried THF $(5-$ $10 \mathrm{~mL}$ ) was added to the solution, and 1,6-dibromohexane (110 $\mathrm{mL}, 0.72 \mathrm{~mol}$ ) was added. This solution was stirred for $2 \mathrm{~h}$ at room temperature and then extracted with ether and washed with water $(3 \times 200 \mathrm{~mL})$. The organic layer was dried over anhydrous $\mathrm{MgSO}_{4}$, filtered, and concentrated.

Distillation at $90-100{ }^{\circ} \mathrm{C}$ at $0.05 \mathrm{mmHg}$ gave the 1 as a colorless oil ( $27.39 \mathrm{~g}, 61 \%$ yield). GC-MS: $t_{r}=11.3 \mathrm{~min},[\mathrm{~m} / \mathrm{z}]$ $=247.20 .{ }^{1} \mathrm{H} \mathrm{NMR}\left(\mathrm{ppm}, \mathrm{CDCl}_{3}\right): 7.24(\mathrm{~d}, 1 \mathrm{H}), 6.92(\mathrm{~d}, 1 \mathrm{H})$, $3.40(\mathrm{t}, 2 \mathrm{H}), 2.64(\mathrm{t}, 2 \mathrm{H}), 1.86(\mathrm{~m}, 2 \mathrm{H}), 1.65(\mathrm{~m}, 2 \mathrm{H}), 1.5(\mathrm{~m}$, $2 \mathrm{H}), 1.2(\mathrm{~m}, 2 \mathrm{H})$.

2-Bromo-3-bromohexylthiophene (3). The compound 3-bromohexylthiophene $(27.39 \mathrm{~g}, 0.11 \mathrm{~mol})$ was dissolved in a mixture of $\mathrm{CHCl}_{3}$ and acetic acid $(135 \mathrm{~mL} / 135 \mathrm{~mL})$. NBS $(23.66$ g, $0.13 \mathrm{~mol}$ ) was added portionwise and stirred for $20 \mathrm{~min}$. The solution was washed with water $(2 \times 200 \mathrm{~mL})$, saturated $\mathrm{NaHCO}_{3}(1 \times 200 \mathrm{~mL})$, and a final wash with water $(1 \times 200$ $\mathrm{mL})$. The organic layer was dried with anhydrous $\mathrm{MgSO}_{4}$, concentrated, and distilled under reduced pressure $\left(120^{\circ} \mathrm{C}\right.$ at $0.5 \mathrm{mmHg}$ ) to recover 3 as a light yellow oil $(16.20 \mathrm{~g}, 45 \%$ yield). GC-MS $t_{r}=12.9 \mathrm{~min},[\mathrm{~m} / \mathrm{z}]=326.09$. ${ }^{1} \mathrm{H} \mathrm{NMR}$ (ppm, $\left.\mathrm{CDCl}_{3}\right): 7.18(\mathrm{~d}, 1 \mathrm{H}), 6.78(\mathrm{~d}, 1 \mathrm{H}), 3.40(\mathrm{t}, 2 \mathrm{H}), 2.58(\mathrm{t}, 2 \mathrm{H})$, $1.87(\mathrm{~m}, 2 \mathrm{H}), 1.61(\mathrm{~m}, 2 \mathrm{H}), 1.51(\mathrm{~m}, 2 \mathrm{H}), 1.39(\mathrm{~m}, 2 \mathrm{H})$.

2-Trimethylstannyl-4-dodecylthiophene (2). Dodecylthiophene (1) $(40 \mathrm{~g}, 0.158 \mathrm{~mol})$ was dissolved in dry THF (400 $\mathrm{mL})$. The solution was cooled to $-40^{\circ} \mathrm{C}$, at which point t-BuLi (2.5 $\mathrm{M}$ in pentane, $102.7 \mathrm{~mL}, 0.158 \mathrm{~mol}$ ) (or LDA) was added dropwise to the solution. U pon addition, a yellow precipitate was formed. The solution was stirred at $-40{ }^{\circ} \mathrm{C}$ for $1 \mathrm{~h}$, followed by addition of trimethylstannyl chloride (1 M/hexane, $174 \mathrm{~mL}, 0.174 \mathrm{~mol})$. The temperature was allowed to reach $25{ }^{\circ} \mathrm{C}$ while stirring over a period of $2 \mathrm{~h}$. Diethyl ether (250 $\mathrm{mL}$ ) was added to the flask, and the solution was extracted with water $(4 \times 300 \mathrm{~mL})$, dried over anhydrous $\mathrm{MgSO}_{4}$, and concentrated. Subsequent Kugel rohr distillation $\left(160-170{ }^{\circ} \mathrm{C}\right.$ at $0.2 \mathrm{mmHg}$ ) gave 2 as a col orless liquid $(40.05 \mathrm{~g}, 61 \%$ yield). GC-MS $\mathrm{t}_{\mathrm{r}}=16.20 \mathrm{~min},[\mathrm{~m} / \mathrm{z}]=415.27$. ${ }^{1} \mathrm{H} \mathrm{NMR}\left(\mathrm{ppm}, \mathrm{CDCl}_{3}\right)$ : $7.19(\mathrm{~s}, 1 \mathrm{H}), 7(\mathrm{~s}, 1 \mathrm{H}), 2.65(\mathrm{~m}, 2 \mathrm{H}), 1.63(\mathrm{~m}, 2 \mathrm{H}), 1.27(\mathrm{~m}$, $8 \mathrm{H}), 0.89(\mathrm{t}, 3 \mathrm{H}), 0.35(\mathrm{t}, 9 \mathrm{H}, 1 \mathrm{~J}(\mathrm{H}-\mathrm{Sn})=27.9 \mathrm{~Hz})$.

3-Dodecyl-3'-bromohexyl-5,2'-bithiophene (4). Compound 2 ( $12.79 \mathrm{~g}, 39.2 \mathrm{mmol})$ was dissolved in DMF $(250 \mathrm{~mL})$. The solution was purged with nitrogen for $15 \mathrm{~min}$, at which time tris(dibenzylideneacetone)dipalladium(0) $\left(\mathrm{Pd}_{2}(\mathrm{dba})_{3}\right)(1.79$ $\mathrm{g}, 1.96 \mathrm{mmol}, 5 \mathrm{~mol} \%)$ and triphenylphosphine $\left(\mathrm{PPh}_{3}\right)(2.05$ $\mathrm{g}, 7.8 \mathrm{mmol}, 20 \mathrm{~mol} \%)$ were added. The solution was warmed to $80{ }^{\circ} \mathrm{C}$, and $\mathbf{3}(24.4 \mathrm{~g}, 58.8 \mathrm{mmol})$ was added. The solution was stirred for $24 \mathrm{~h}$ at $80^{\circ} \mathrm{C}$. The mixture was then cooled to room temperature and filtered. After filtration, the solution was diluted with ether and washed with water $(3 \times 150 \mathrm{~mL})$. The organic layer was dried over $\mathrm{MgSO}_{4}$ and concentrated. Purification was carried out via silica gel column chromatography, using hexanes as the eluent. After concentration, $\mathbf{4}$ was obtained as a pale yellow oil ( $13.1 \mathrm{~g}, 49 \%$ yield). ${ }^{1} \mathrm{H}$ NMR (ppm, $\left.\mathrm{CDCl}_{3}\right): 7.12(\mathrm{~d}, 1 \mathrm{H}), 6.9(\mathrm{~d}, 1 \mathrm{H}), 6.88(\mathrm{~s}, 1 \mathrm{H}), 6.87(\mathrm{~s}, 1 \mathrm{H})$, $3.37(\mathrm{t}, 2 \mathrm{H}), 2.75(\mathrm{t}, 2 \mathrm{H}), 2.59(\mathrm{t}, 2 \mathrm{H}), 1.86(\mathrm{~m}, 2 \mathrm{H}), 1.63(\mathrm{~m}$, $2 \mathrm{H}), 1.26(\mathrm{~m}, 24 \mathrm{H}), 0.87(\mathrm{t}, 3 \mathrm{H})$. Elemental analysis (\%): Calculated: C, 65.75; H, 8.30; S, 12.89; $\mathrm{Br}, 16.06$. Found: C, 64.43; H, 8.68; S, 12.41; $\mathrm{Br}, 16.24$.

2-Bromo-3-dodecyl-3-bromohexyl-5,2-bithiophene.Compound 4 (12.83 g, $30.7 \mathrm{mmol})$ was dissolved in THF $(130 \mathrm{~mL})$, and the solution was cooled to $0^{\circ} \mathrm{C}$. Recrystallized NBS $(6.02$ $\mathrm{g}, 33.8 \mathrm{mmol}$ ) is added portionwise. The solution was stirred 
for $20 \mathrm{~min}$ at $0{ }^{\circ} \mathrm{C}$. After this time, the organic layer was diluted with ether and washed with water $(3 \times 100 \mathrm{~mL})$. The organic layer was dried over $\mathrm{MgSO}_{4}$ and concentrated. Purification was performed using hexanes as an eluent on a silica gel chromatographic column. The title compound was recovered as a pale yellow oil ( $11.93 \mathrm{~g}, 67 \%$ yield). ${ }^{1} \mathrm{H}$ NMR (ppm, $\left.\mathrm{CDCl}_{3}\right)$ : $7.14(\mathrm{~d}, 1 \mathrm{H}), 6.88(\mathrm{~d}, 1 \mathrm{H}), 6.77(\mathrm{~s}, 1 \mathrm{H}), 3.38(\mathrm{t}, 2 \mathrm{H})$, $2.71(\mathrm{t}, 2 \mathrm{H}), 2.55(\mathrm{t}, 2 \mathrm{H}), 1.84(\mathrm{~m}, 2 \mathrm{H}), 1.62(\mathrm{~m}, 2 \mathrm{H}), 1.26(\mathrm{~m}$, $24 \mathrm{H}), 0.87(\mathrm{t}, 3 \mathrm{H})$

2-Bromo-3-dodecyl-3'-(diethylhexylphosphonate)-5,2 bithiophene (5). 2-Bromo-3-dodecyl-3'-bromohexyl-5,2'-bithiophene $(6.42 \mathrm{~g}, 12.9 \mathrm{mmol})$ and triethyl phosphite $(8.88 \mathrm{~mL}$, $51.7 \mathrm{mmol}$ ) were placed in a round-bottom flask with an attached distillation head for removal of byproducts. The solution was stirred at $140{ }^{\circ} \mathrm{C}$ for $18 \mathrm{~h}$. Afterward, triethyl phosphite was removed in vacuo from the reaction flask. The remaining oil was purified on a silica gel chromatography column using ethyl acetate/hexanes (1:1) as eluent. After purification, $5(6.34 \mathrm{~g}, 88 \%$ yield) was recovered as a pale yellow oil. ${ }^{1} \mathrm{H}$ NMR (ppm, $\left.\mathrm{CDCl}_{3}\right)$ : $7.14(\mathrm{~d}, 1 \mathrm{H}), 6.87(\mathrm{~d}, 1 \mathrm{H})$, $6.77(\mathrm{~s}, 1 \mathrm{H}), 4.07(\mathrm{~m}, 4 \mathrm{H}), 2.69(\mathrm{t}, 2 \mathrm{H}), 2.55(\mathrm{t}, 2 \mathrm{H}), 1.75(\mathrm{t}$, $2 \mathrm{H}), 1.60(\mathrm{~m}, 6 \mathrm{H}), 1.31(\mathrm{t}, 6 \mathrm{H}), 1.26(\mathrm{~m}, 22 \mathrm{H}), 0.87(\mathrm{t}, 3 \mathrm{H})$. Elemental analysis (\%): Calculated: $\mathrm{C}, 56.86$; $\mathrm{H}, 7.95$; $\mathrm{S}$, 10.12; $\mathrm{Br}, 12.61 ; \mathrm{P}, 4.89$. Found: C, 57.05; H, 8.11; S, 10.35; $\mathrm{Br}, 12.62 ; \mathrm{P}, 4.74$

2-Bromo-3-dodecyl-3'-(diethylhexylphosphonate)-5'tributyltin-5,2'-bithiophene (6). LDA was generated by addition at $-70{ }^{\circ} \mathrm{C}$ of BuLi $(2.5 \mathrm{M} /$ hexanes, $3.33 \mathrm{~mL}, 8.33$ $\mathrm{mmol})$ to a solution of diisopropylamine $(1.16 \mathrm{~mL}, 8.33 \mathrm{mmol})$ in THF (20 mL). Compound $\mathbf{5}(3.84 \mathrm{~g}, 6.94 \mathrm{mmol})$ was added dropwise to the LDA solution, keeping the temperature bel ow $-70{ }^{\circ} \mathrm{C}$. The reaction mixture was stirred for $1 \mathrm{~h}$ at $-70{ }^{\circ} \mathrm{C}$. Tributyltin chloride $(2.07 \mathrm{~mL}, 7.63 \mathrm{mmol})$ was added at -70 ${ }^{\circ} \mathrm{C}$, and the solution was stirred for $1 \mathrm{~h}$. The mixture was then warmed to room temperature over the course of $1 \mathrm{~h}$. The solution was diluted with ether and washed with water $(3 \times$ $25 \mathrm{~mL}$ ). The organic layer was dried over anhydrous $\mathrm{MgSO}_{4}$ and concentrated. The resulting resi due was purified by silica gel column chromatography el uted with hexanes/ethyl acetate (8:2) to receive $6\left(1.27 \mathrm{~g}, 21 \%\right.$ yiel d) as a colorless oil. ${ }^{1} \mathrm{H}$ NMR (ppm, $\left.\mathrm{CDCl}_{3}\right): 6.91(\mathrm{~s}, 1 \mathrm{H}), 6.77(\mathrm{~s}, 1 \mathrm{H}), 4.09(\mathrm{~m}, 4 \mathrm{H}), 2.72(\mathrm{t}$, $2 \mathrm{H}), 2.55(\mathrm{t}, 2 \mathrm{H}), 1.75(\mathrm{t}, 2 \mathrm{H}), 1.55(\mathrm{~m}, 6 \mathrm{H}), 1.31(\mathrm{t}, 6 \mathrm{H}), 1.26$ $(\mathrm{m}, 32 \mathrm{H}), 1.10(\mathrm{~m}, 6 \mathrm{H}), 0.87(\mathrm{~m}, 12 \mathrm{H})$. Elemental analysis (\%): Calculated: C, 55.13; H, 8.39; S, 6.85; P, 3.31. Found: C, 54.31; H, 8.22; S, 8.01; P, 3.99.

Poly(3-dodecyl-3' -(diethylhexylphosphonate)-5,2' bithiophene) (7) Synthesis. Compound 6 ( $2.22 \mathrm{~g}, 2.37 \mathrm{mmol}$ ) was dissolved in DMF $(50 \mathrm{~mL})$. The solution was purged with dry nitrogen for $15 \mathrm{~min}$. $\mathrm{Pd}_{2}(\mathrm{dba})_{3}(108 \mathrm{mg}, 0.118 \mathrm{mmol}, 5 \mathrm{~mol}$ $\%$ ) and $\mathrm{PPh}_{3}$ (124 mg, $0.474 \mathrm{mmol}, 20 \mathrm{~mol} \%$ ) were added, and the solution was stirred overnight at $80^{\circ} \mathrm{C}$. The solution was cooled to room temperature and poured into water $(1 \mathrm{~L})$ to precipitate the polymer. After filtration, the polymer was dissolved in $\mathrm{CHCl}_{3}$ and washed with water to remove residual DMF. The chloroform solution was dried over anhydrous $\mathrm{MgSO}_{4}$, concentrated, and poured into hexanes $(500 \mathrm{~mL})$ to reprecipitate polymer, followed by another filtration step. The polymer was then subjected to a Soxhlet extraction in hexanes to remove impurities with a subsequent chloroform Soxhlet extraction to recover high molecular weight polymer $7(0.428$ $\mathrm{g}, 33 \%$ yield). $M_{\mathrm{n}}(\mathrm{GPC})=21500 \mathrm{~g} / \mathrm{mol} ; \mathrm{PDI}(\mathrm{GPC})=1.46$. $\mathrm{M}_{\text {range }}(\mathrm{MALDITOF}-\mathrm{MS})=6000-11000 \mathrm{~g} / \mathrm{mol}$. UV $\lambda_{\max }$ (thin film) $=542 \mathrm{~nm}, \lambda_{\max }\left(\mathrm{CHCl}_{3}\right)=443 \mathrm{~nm} .{ }^{1} \mathrm{H} \mathrm{NMR}\left(\mathrm{ppm}, \mathrm{CDCl}_{3}\right)$ : $6.89(\mathrm{~s}, 2 \mathrm{H}), 4.01(\mathrm{~m}, 4 \mathrm{H}), 2.72(\mathrm{t}, 4 \mathrm{H}), 1.61(\mathrm{~m}, 8 \mathrm{H}), 1.18(\mathrm{~m}$, $30 \mathrm{H}), 0.79(\mathrm{~m}, 3 \mathrm{H})$. Elemental analysis (\%): Calculated: $\mathrm{C}$, 64.94; H, 9.26; P, 5.58. Found: C, 62.57; H, 8.62; P, 5.77

Poly(3-dodecyl-3'-(hexylphosphonic acid)-5,2 -bithiophene) (8). Polymer 7 (520 mg, 52 umol) was dissolved in $\mathrm{CH}_{2-}$ $\mathrm{Cl}_{2}$. Bromotrimethylsilane (4 equiv, $0.5 \mathrm{~mL}, 3.7 \mathrm{mmol}$ ) and triethylamine $(0.5 \mathrm{~mL}, 3.7 \mathrm{mmol})$ were added, and the solution was stirred for $12 \mathrm{~h}$. The solvent was removed under vacuum, and methanol (15 mL) was added. The resulting purple suspension was stirred for $8 \mathrm{~h}$. The flask was then subjected to vacuum to remove solvents and remaining reagents. Once dry, the polymer was insoluble in its native state but solubi- lized as its tetraalkylammonium salt in solution in water. The resulting salt has differing col ors depending on the size of the counterion. Red solution with $\mathrm{Bu}_{4} \mathrm{~N}^{+}: \mathrm{UV}$ (water): $\lambda_{\max }=497$ $\mathrm{nm}$. Purple solution with $\mathrm{Pr}_{4} \mathrm{~N}^{+}$: UV (water): $\lambda_{\max }=534 \mathrm{~nm}$. Purple solution with $\mathrm{Et}_{4} \mathrm{~N}^{+}$: UV (water): $\lambda_{\max }=532 \mathrm{~nm}$.

2-B romo-3-(hexyl(6-diethylphosphonate))thiophene (11). In a round-bottom flask fitted for a simple distillation for removal of byproducts, compound $\mathbf{3}(7.5 \mathrm{~g}, 23.0 \mathrm{mmol})$ was dissolved in triethyl phosphite $(12 \mathrm{~mL}, 80 \mathrm{mmol})$ and heated to $140{ }^{\circ} \mathrm{C}$ for $16 \mathrm{~h}$. Following this period, the reaction was then followed by a vacuum distillation of the product (200 C, $0.5 \mathrm{~T}$ ) to give 11 as a colorless oil $\left(8.08 \mathrm{~g}, 92 \%\right.$ yield). GC-MS: $\mathrm{t}_{\mathrm{r}}=$ $17.0 \mathrm{~min}(250 \mathrm{C}) ;\left[\mathrm{M}^{+}\right]=\mathrm{m} / \mathrm{z} 303 .{ }^{1} \mathrm{H}$ NMR: $\left(p p m, \mathrm{CDCl}_{3}\right) 6.8$ $(\mathrm{d}, \mathrm{J}=6 \mathrm{~Hz}) ; 5.4(\mathrm{~m}) ; 2.5(\mathrm{t}, \mathrm{J}=7 \mathrm{~Hz}) ; 1.5-1.8(\mathrm{~b}, \mathrm{~m}) ; 1.3(\mathrm{t}$, $=6 \mathrm{~Hz}$ ).

2-Bromo-3-(hexyl(6-diethylphosphonate))-5-(tributylstannyl)thiophene (12). To a three-neck round-bottom flask THF (30 mL) was added and $\mathbf{1 1}(2.14 \mathrm{~g}, 5.5 \mathrm{mmol})$ was added and stirred to dissolution at $-70^{\circ} \mathrm{C}$. In a separate flask, LDA was made (1.1 equiv) followed by transfer to the cool ed reaction flask via cannula. The transfer was completed while keeping the reaction temperature below $-70{ }^{\circ} \mathrm{C}$. Upon complete addition of the LDA, the mixture was allowed to stir at low temperature. After $1 \mathrm{~h}$, tributyltin chloride ( $1.49 \mathrm{~mL}, 1$ equiv) was added to the solution and allowed to stir for $1.5 \mathrm{~h}$ at -70 ${ }^{\circ} \mathrm{C}$. The solution was then warmed to room temperature and then extracted mixed with water $(50 \mathrm{~mL})$, to which diethyl ether was added $(100 \mathrm{~mL})$. The ether layer was then washed with water $(3 \times 100 \mathrm{~mL})$, dried over $\mathrm{Na}_{2} \mathrm{SO}_{4}$, and the solvent removed in vacuo. The product was then visualized through TLC $\left(R_{f}=0.42\right.$, mobile hexanes:ethyl acetate, 1:9; stationary silica) and separated by flash chromatography to give $\mathbf{1 2}$ as a pale yellow oil (1.5 g, 40.5\% yield). ${ }^{1} \mathrm{H}$ NMR: $\left(\mathrm{CDCl}_{3}, \delta\right) 0.9$, $1.1,1.3,1.5-1.8(\mathrm{~m}) ; 2.6(\mathrm{t}, \mathrm{J}=9 \mathrm{~Hz}) ; 4.1(\mathrm{~m}) ; 6.8(\mathrm{t}, \mathrm{J}=9$ $\mathrm{Hz}$.

2,5-Poly-3-(6-hexyl-(diethylphosphonate)thiophene) (13). To a three-neck round-bottom flask set up for reflux was added N,N-dimethylformamide (35 mL) and 12 (1.5 g, 2.2 $\mathrm{mmol}$ ). The solution was stirred to dissolution and sparged with nitrogen for $20 \mathrm{~min}$. After the purging period, $\mathrm{PPh}_{3}(42$ mg, 0.1 equiv) and $\mathrm{Pd}_{2}(\mathrm{dba})_{3}(50 \mathrm{mg}, 0.025$ equiv) were added to the solution, which immediately turned opaque black. The solution was then stirred and heated to reflux for $16 \mathrm{~h}$. The resulting solution was then poured into water $(900 \mathrm{~mL})$ and extracted with $\mathrm{CHCl}_{3}$ until the aqueous phase was no longer orange. The collected $\mathrm{CHCl}_{3}$ extractions were then placed on the rotary evaporator, and the residue redissolved in $\mathrm{CHCl}_{3}$ $(350 \mathrm{~mL})$. This was then washed with water $(6 \times 300 \mathrm{~mL})$. The solvent from the organic layer was removed in vacuo, and the resulting purple residue was then dissolved in a minimal amount of $\mathrm{CHCl}_{3}$. The concentrated solution of polymer was then precipitated in hexanes $(700 \mathrm{~mL})$ which was filtered through a cellulose filter thimble and a Soxhlet extraction in hexanes. A second Soxhlet extraction was then attempted with THF . M ost of the polymer was removed in this step giving high molecular weight 13. ${ }^{1} \mathrm{H} \mathrm{NMR}:\left(\mathrm{CDCl}_{3}, \delta\right) 1.3,1.4,1.5-1.9$, 2.1 (b); $2.8(\mathrm{t}, \mathrm{b}) ; 4.1(\mathrm{~m}) ; 6.98(\mathrm{~s}) . \mathrm{GPC}\left(\mathrm{CHCl}_{3}, \mathrm{PS}\right.$ standard $)$ $M_{n}=13110 \mathrm{~g} \mathrm{~mol}^{-1} ; M_{w}=25050 \mathrm{~g} \mathrm{~mol}^{-1} ; P D I=1.91$. MALDI-TOF-MS (matrix: terthiophene): $M=2425-6955 \mathrm{~g}$ $\mathrm{mol}^{-1}$. UV/vis (thin film): $\lambda_{\max }=524 \mathrm{~nm} ;\left(\mathrm{CHCl}_{3}\right): \lambda_{\max }=442$ $\mathrm{nm}$

2,5-Poly-3-(hexyl-6-phosphonic acid)thiophene (14). Polymer $\mathbf{1 3}$ (880 mg, 3 mmol) was placed in a three-neck flask and dissolved in methylene chloride $(75 \mathrm{~mL})$. To this, bromotrimethylsilane $(3.67 \mathrm{~g}, 24 \mathrm{mmol})$ and triethylamine $(2.40 \mathrm{~g}$, $24 \mathrm{mmol}$ ) were added. The solution was stirred overnight. After the stirring period, the methylene chloride was removed, and methanol $(100 \mathrm{~mL})$ was added to the flask and stirred for $2 \mathrm{~h}$. The resulting residue was insoluble in organic solvents but was readily solvated in water as the tetraal kylammonium salt. Orange solution with $\mathrm{NaOH}$ : UV (water): $\lambda_{\max }=428 \mathrm{~nm}$. Red solution with $\mathrm{Bu}_{4} \mathrm{~N}^{+}$: UV (water): $\lambda_{\max }=465 \mathrm{~nm}$. Purple solution with $\mathrm{Pr}_{4} \mathrm{~N}^{+}$: UV (water): $\lambda_{\max }=465 \mathrm{~nm}$. Purple solution with $\mathrm{Et}_{4} \mathrm{~N}^{+}$: UV (water): $\lambda_{\max }=460 \mathrm{~nm}$. Purple solution with $\mathrm{H}_{4} \mathrm{~N}^{+}$: UV (water): $\lambda_{\max }=510 \mathrm{~nm}$. 
Acknowledgment. We are very grateful to the NSF (CHE 0107178) for support of our work.

\section{References and Notes}

(1) Lee, H.; Kepley, L. J .; Hong, H.-G.; Mallouk, T. E. J . Am. Chem. Soc. 1988, 110, 618.

(2) (a) Petruska, M. A.; Talham, D. R. Chem. Mater. 1998, 10, 3672. (b) Petruska, M. A.; Fanucci, G. E.; Talham, D. R. Chem. Mater. 1998, 10, 177. (c) Byrd, H.; Pike, J . K.; Talham, D. R. Chem. Mater. 1993, 5, 709.

(3) (a) Garnier, F.; Hajlaoui, R.; Y assar, A.; Srivastava, P. Science (Washington, D.C.) 1994, 265, 1684. (b) Katz, H. E.; Schilling, M. L.; Chidsey, C. E. D.; Putvinski, T. M.; Hutton, R. S. Chem. Mater. 1991, 3, 699.

(4) (a) Berlin, A.; Zotti, G. Macromol. Rapid Commun. 2000, 21, 301. (b) Faïd, K.; Leclerc, M. J . Am. Chem. Soc. 1998, 120, 5274.
(5) McCullough, R. D.; E wbank, P. C. In Handbook of Conducting Polymers, 2nd ed.; Skotheim, T. A., Elsenbaumer, R. L., Reynolds, J. R., Eds.; Dekker: New York, 1998; p 225.

(6) Heuzé, K.; McCullough, R. D. Polym. Prepr. 1999, 40 (2), 854.

(7) Reports of phosphonate ester functionalized polythiophenes have been reported. See: (a) Kowalik, J ;; Tol bert, L. M. Chem Commun. 2000, 877. (b) Viinikavoja, A.; Lukkar, J .; Aaritalo, T.; Laiho, T.; Kankare, J. Langmuir 2003, 19, 2268.

(8) McCullough, R. D.; Ewbank, P. C.; Loewe, R. S. J . Am. Chem. Soc. 1997, 119, 633.

(9) Lowe, R. D.; McCullough, R. D. J . Chem. Soc., Chem. Commun. 1992, 70.

(10) Loewe, R. S.; Khersonsky, S. M.; McCullough, R. D. Adv. Mater. 1999, 11, 250.

(11) Wu, X.; Chen, T.-A.; Zhu, L.; Rieke, R. D. Tetrahedron Lett. 1994, 35, 3673.

MA034639+ 